\title{
Evaluation of serum levels of iron, total iron binding capacity, transferrin saturation and ferritin in chronic kidney disease patients vs. control group
}

\author{
Hafsatu Maiwada Suleiman, ${ }^{1}$ Mohammed Amina, ${ }^{2}$ Ibrahim Abubakar, ${ }^{1}$ Yusuf Rasheed, ${ }^{1}$ \\ Mohammed Jibril El-Bashir, ${ }^{1}$ Mohammed Manu, ${ }^{1}$ Bello Jamoh, ${ }^{1}$ Amina Dogara Bashir ${ }^{1}$ \\ ${ }^{1}$ Ahmadu Bello University/Ahmadu Bello University Teaching Hospital, Zaria; ${ }^{2}$ Federal Medical Centre, \\ Bida, Nigeria
}

\begin{abstract}
The magnitude of chronic renal disease is enormous, as the prevalence of kidney failure is rising. Anaemia is a common complication of chronic kidney disease (CKD) that develops early in its course and becomes increasingly severe as the disease progresses. The aim is to evaluate the serum level of iron, Total Iron Binding Capacity (TIBC), transferrin saturation and ferritin in chronic kidney disease population in Zaria and control subjects. This study was conducted at ABUTH Zaria were 125 patients in various stages of CKD who presented at the nephrology clinic and equal number of apparently healthy age and sex matched controls were recruited. The mean (SD) age of patient and controls were 48 (14) years. These were made up of $53.6 \%$ males, and $46.4 \%$ females. Mean values of serum creatinine significantly higher in the patients $(<0.0001)$. There was no significant difference in the mean values of iron $(\mathrm{p}=0.32)$ and TIBC $(\mathrm{p}=1.29)$ in both study groups. The patients had a significantly $(\mathrm{p}<0.0001)$ higher mean value for ferritin and TSAT than the control group. There were higher serum creatinine and ferritin values in males than in females while higher serum TIBC, estimated creatinine clearance and iron were observed in females than males. Serum creatinine, ferritin
\end{abstract}

Correspondence: Hafsatu Maiwada Suleiman, Department of Chemical Pathology, Ahmadu Bello University, Zaria, Nigeria.

Tel.: +2348037013611.

E-mail: suleimanhafsatu@yahoo.com

Key words: Chronic kidney disease, Total Iron Binding Capacity, Transferrin Saturation, Ferritin, Estimated GFR.

Contributions: HMS, data analysis, statistical analysis, manuscript preparation and review; MA, concept and design; IA, clinical study; YR, manuscript editing; MJE, data acquisition; MM, literature search; $\mathrm{BJ}$, guarantor for the manuscript; $\mathrm{ADB}$, experimental study.

Conflict of interest: The authors declare no potential conflict of interest.

Funding: None.

Received for publication: 22 January 2020.

Accepted for publication: 12 February 2020.

This work is licensed under a Creative Commons Attribution NonCommercial 4.0 License (CC BY-NC 4.0).

CCopyright: the Author(s), 2019

Licensee PAGEPress, Italy

Annals of African Medical Research 2019; 2:101

doi:10.4081/aamr.2019.101 and estimated creatinine clearance of male patients were found to be significantly higher with p-value of $0.002,0.000$ and 0.028 respectively than that of female patients. No significant differences were noted in serum levels of iron, TIBC and TSAT. Serum creatinine, ferritin and TSAT were found to be significantly elevated in CKD patients while serum Iron and TIBC were not.

\section{Introduction}

Chronic kidney disease (CKD) is defined as either damage or a decreased Glomerular Filtration Rate (GFR) of less than 60 $\mathrm{ml} / \mathrm{min} / 1.73 \mathrm{~m}^{2}$ for 3 or more months. Whatever the underlying aetiology, the destruction of renal mass with irreversible sclerosis and loss of nephrons leads to a progressive decline in GFR. The different stages of kidney disease form a continuum in time. ${ }^{1,2}$

The burden of CKD is enormous, as the prevalence of kidney failure is rising. Indeed, a recent evidence indicates that $\mathrm{CKD}$ is emerging as a worldwide public health problem, being associated with increased cardiovascular mortality and a loss of disabilityadjusted life years. ${ }^{3}$ Globally CKD represents the $12^{\text {th }}$ cause of death and $17^{\text {th }}$ cause of disability. 3,4

Anaemia is a common complication of CKD that develops early in the course of CKD, and becomes increasingly severe as the disease progresses. It affects $60-80 \%$ of patients with renal impairment, reduces the quality of life and is an additional risk factor for early death. The management of anaemia in CKD patients requires an appropriate balance between stimulating the erythropoiesis and maintaining sufficient iron levels for optimum haemoglobin $(\mathrm{Hb})$ production. Erythropoiesis and iron homeostasis are impaired as a result of a complex chain of events, including the relative deficiency of erythropoietin, chronic inflammation, blood loss, decreased iron absorption and utilization, exogenous iron and erythropoietin acquisition via biologically unregulated mechanisms (such as blood transfusions and medicinal erythropoietin and iron administration). ${ }^{5}$

Therefore, it seems reasonable to assume that early detection of biochemical derangements will, facilitate appropriate interventions which will impact on progression of CKD. Despite the seeming benefit of early detection of the biochemical complications of CKD, there is paucity of data in patients with CKD in Nigeria. Hence the aim of this study was to determine serum level of iron, Total Iron Binding Capacity (TIBC), transferrin saturation and ferritin among chronic kidney disease patients in Zaria, Nigeria.

\section{Materials and Methods}

This was a comparative cross-sectional case control study in which 125 consecutive adult patients in various stages of chronic kidney disease (CKD) who presented at the nephrology clinic of 
ABUTH Shika Zaria were enrolled. An equal number of subjects, matched for sex and age were selected from the University population and neighboring villages to serve as controls. Those that had history of blood transfusion in the last three months were pregnant, severely morbid patients and Those with clinical evidence of liver disease where excluded from the study. The sample size for the study was determined from a standard formula for the calculation of minimum sample size. ${ }^{6}$

Estimated sample size was calculated using the formula below:

$$
\mathrm{n}=\mathrm{z}^{2} \mathrm{pq} / \mathrm{d}^{2}
$$

$\mathrm{n}=$ sample size, $\mathrm{z}=$ confidence interval (1.96), $\mathrm{d}=$ precision $(0.05)$, $\mathrm{p}=$ prevalence of CKD in ile Ife $(8 \%), q=1-p$

$$
\mathrm{n}=(1.96)^{2} \times 0.080 \times 0.920 /(0.05)^{2}=113.1
$$

one hundred and twenty-five (125) chronic kidney disease patients and another 125 apparently healthy age matched controls were recruited.

Approval was obtained from Ahmadu Bello University Teaching Hospital Health Research Ethics committee Zaria (ABUTH/HREC/F7/2013) before embarking on the study.

Five milliliters $(5 \mathrm{~mL})$ of blood specimen was collected from a prominent peripheral vein. The antecubital fossa was cleaned with $70 \%$ methylated spirit and allowed to dry. Blood was taken using a sterilized $5 \mathrm{~mL}$ syringe and $21 \mathrm{G}$ needle. $5 \mathrm{~mL}$ of the blood sample was transferred into a plain sample bottle and allowed to stand for 30 minutes to clot and thereafter was centrifuged at 4000rpm for $10 \mathrm{~min}$. The serum was separated immediately and transferred into a serum bottle and was stored frozen at $-20^{\circ} \mathrm{C}$ until time for analysis.

The following biochemical investigations were performed on all study subjects viz: iron, ferritin, iron binding globulin (transfer- rin), Transferrin saturation (TSAT) was calculated by dividing serum iron by transferrin and multiplying by 100 . Serum creatinine was measured and estimated creatinine clearance $(\mathrm{eCrCl})$ was calculated by the use of prediction equation using Cockcroft and Gault formula. ${ }^{1}$

$\mathrm{eCrCl}=140-$ age $(\mathrm{yr}) \times \mathrm{wt}(\mathrm{kg}) \times 1.2 / \mathrm{cr}(\mathrm{umol} / \mathrm{l})$ for male

$=140-$ age $(\mathrm{yr}) \times \mathrm{wt}(\mathrm{kg}) \times 1.2 \times 0.85 / \mathrm{cr}(\mathrm{umol} / \mathrm{l})$ for female

The chemicals and kits used for the measurement of serum iron, transferrin (TIBC) and creatinine were procured commercially from Labkit Barcelona Spain and ferritin was procured from performed diagnostic system san Francisco USA. All chemicals and kits were of analytical grade.

\section{Analytical methods}

\section{Measurement of serum iron}

Serum iron was analysed using thiocyanide method, ${ }^{7}$ while serum TIBC was analysed using Ferrozine method, ${ }^{8}$ serum ferritin was analysed using Perlmann and Engvall, 1973 Elisa method, while creatinine was analysed using modified Jaffes method of Folin $1886^{10}$

\section{Statistical analysis}

The data was analyzed using Statistical Package for the Social Sciences 17.0 (SPSS 17.0) for windows (SPSS inc. Chicago, 17). Serum iron, total iron binding capacity, ferritin, creatinine obtained from the patients was compared with those of the controls using the two tailed student's t-test. Categorical data were summarized as frequencies and percentages while continues data were summarized as means \pm standard deviations. Students-t-test will be used to analyzed continues normally distributed variables and man Whitney test for continues non-normally distributed variables.

\begin{tabular}{|c|c|c|c|c|}
\hline Characteristics & Healthy & $(n=125)$ & \multicolumn{2}{|c|}{ CKD Patients $(n=125)$} \\
\hline Age, mean (SD)* & $48(14)$ & \multicolumn{3}{|c|}{$48(14)$} \\
\hline Sex Ratio M:F & 1.15: 1 & \multicolumn{3}{|c|}{ 1.15: 1} \\
\hline Male & 67 & $53.6 \%$ & 67 & $53.66 \%$ \\
\hline Female & 58 & $46.46 \%$ & 58 & $46.46 \%$ \\
\hline \multicolumn{5}{|c|}{ Highest level of education attained } \\
\hline Primary & 9 & $7.26 \%$ & 24 & $19.26 \%$ \\
\hline Secondary & 23 & $18.46 \%$ & 35 & $28.06 \%$ \\
\hline Tertiary & 56 & $44.86 \%$ & 30 & $24.06 \%$ \\
\hline None & 37 & $29.66 \%$ & 36 & $28.86 \%$ \\
\hline
\end{tabular}

Table 1. Sociodemographic characteristics of the study population.

*P-value: 0.988

\begin{tabular}{|c|c|c|c|}
\hline Characteristics & $\begin{array}{c}\text { Controls ( } \mathrm{n}=125) \\
\text { Mean (SD) }\end{array}$ & $\begin{array}{c}\text { Patients }(\mathrm{n}=125) \\
\text { Mean (SD) }\end{array}$ & p-value \\
\hline Age (years) & $48(14)$ & $48(14)$ & 0.988 \\
\hline Systolic BP (mmHg) & $126.12(18.71)$ & $147.45(28.21)$ & $<0.001$ \\
\hline Diastolic BP (mmHg) & $78.64(10.63)$ & $92.61(18.12)$ & $<0.001$ \\
\hline BMI $\left(\mathrm{kg} / \mathrm{m}^{2}\right)$ & $24.81(6.09)$ & $26.39(6.49)$ & 0.48 \\
\hline Creatinine (umol/l) & $81.47(27.43)$ & $623.88(681.54)$ & $<0.001$ \\
\hline $\mathrm{eCrCl}\left(\mathrm{ml} / \mathrm{min} / 1.73 \mathrm{~m}^{2}\right)$ & $93.93(42.43)$ & $36.28(35.44)$ & $<0.001$ \\
\hline Serum iron (umol/l) & $17.59(8.91)$ & $20.21(10.23)$ & 0.32 \\
\hline Serum TIBC (umol//) & $66.22(23.92)$ & 71.27 (28.23) & 1.29 \\
\hline
\end{tabular}

Table 2. Clinical and Laboratory characteristic of healthy control subjects and patients with CKD. 
Also, the correlation of analytes with eGFR was carried out using Pearson's linear correlation analysis. A p-value $\leq 0.05$ as considered statistically significant.

\section{Results}

One hundred and twenty-five (125) chronic kidney disease patients (CKD) aged 18 to 85 years were recruited for the study with a mean \pm SD age of $48 \pm 14$ years. These were made up of 67 $(53.6 \%)$ males; their level of educational attainment showed that $35.6 \%$ of them had tertiary education, $33 \%$ had secondary education while $13.2 \%$ had primary education as shown in Table 1.

Table 2 shows the mean age, systolic blood pressure, diastolic blood pressure, and body mass index of both controls and patients in CKD. Higher systolic blood pressure as well as diastolic blood pressure and BMI were recorded in patients compared with controls. There was statistically significant difference $(p<0.00)$ between the mean systolic blood pressure and diastolic blood pressure in both patients and controls. There is no significant difference statistically between mean body mass index in patients and controls. Table 1 also showed mean serum levels of creatinine, iron, TIBC and TSAT in patients and controls with mean values of serum creatinine significantly higher in the patients $(p<0.000)$. There was no significant difference in the mean values of iron $(p=0.32)$ and TIBC $(p=1.29)$ in both study groups. The patients had a significantly $(p<0.000)$ higher mean value for ferritin than the control group. The differences between males and female CKD patients in serum creatinine, ferritin and estimated creatinine clearance were found to be statistically significant with $\mathrm{p}$ value of $0.002,0.000$ and 0.028 respectively. No statistical significant differences were noted in serum levels of iron, TIBC and TSAT as shown in Table 3. Normal iron status was seen in $81(64.8 \%)$ CKD patients. Absolute iron deficiency was seen in 16\% Functional iron deficiency was seen in $19.2 \%$. None had iron overload as shown in Table 4.

Table 3. Comparison of serum levels of iron, creatinine, TIBC, TSAT, ferritin and $\mathrm{eCrCl}$ in males and females $\mathrm{CKD}$ patients.

\begin{tabular}{lccc}
\hline Analyses & Male & Female & p-value \\
Creatinine (umol/l) & $793.8 \pm 754$ & $427.5 \pm 527$ & 0.002 \\
TIBC (umol/ $)$ & $67.39 \pm 30.81$ & $75.74 \pm 24.41$ & 0.094 \\
\hline Iron $(\mathrm{umol} / \mathrm{l})$ & $20.14 \pm 10.27$ & $20.28 \pm 10.27$ & 0.094 \\
Tsat $(\%)$ & $33.44 \pm 19.30$ & $30.11 \pm 21.64$ & 0.370 \\
\hline Ferritin $(\mathrm{ng} / \mathrm{ml})$ & $250.68 \pm 134.58$ & $164.82 \pm 128.85$ & $<0.001$ \\
eCrcl $\left(1.73 \mathrm{~m}^{2} / \mathrm{ml} / \mathrm{min}\right)$ & $29.80 \pm 30.97$ & $43.75 \pm 38.93$ & 0.028 \\
\hline
\end{tabular}

Table 4. Iron status among CKD patients.

\begin{tabular}{lc} 
Iron status & Patients $\mathrm{n}=\mathbf{1 2 5}$ \\
Normal iron status & $81(64.8 \%)$ \\
Absolute iron deficiency & $20(16 \%)$ \\
\hline Functional iron deficiency & $24(19.2 \%)$ \\
Iron overload & $0(0 \%)$ \\
\hline
\end{tabular}

\section{Discussion}

Mean serum creatinine of $628 \mathrm{umol} / 1$ and estimated creatinine clearance of $(\mathrm{eCrCl}) 36.28 \mathrm{ml} / \mathrm{min} / \mathrm{m}^{2}$, was found in patients with CKD in this study. This is similar to the work Chijioke et al. in Ilorin $(2011)^{11}$ which was also estimated by the validated Cockroft and Gault formula with a creatinine of $671.9-\mathrm{mol} / \mathrm{l}$ and $\mathrm{eCrCl}$ of 34 $\mathrm{ml} / \mathrm{min} / \mathrm{m}^{2}$. This high mean creatinine levels may reflect the late presentation of majority of CKD patients in the study. This was also reported by Chinwuba et al. in Enugu in $2010^{12}$ while assessing the enormity of CKD.

The mean serum Iron TSAT and ferritin and TIBC found in our study was similar to the work of Srikanth et al. (2010) ${ }^{13}$ in India on the predictive value of iron store markers in anaemia of CKD in 207 CKD patients. They had mean serum levels of iron 15.09umol/1, TIBC of $46.54 \mathrm{umol} / 1$, ferritin of $272.66 \mathrm{ng} / \mathrm{ml}$ and TSAT of $29.1 \%$. Except for TIBC which was higher in our study and can be attributed to the slightly higher levels in serum iron and TSAT.

The serum iron levels were higher in patients than in controls. The difference was not statistically significant. This may be because our CKD patients were on iron supplement as part of their treatment protocol as recommended by KDOQI guidelines. TSAT is an indicator of circulating iron and the positive association with serum iron found in this study reflects the availability of sufficient iron in the form of iron bound with transferrin.

Serum levels of ferritin in our study was similar to the findings of Chijioke et al. ${ }^{11}$ in Ilorin who reported ferritin level of $194 \mathrm{ng} / \mathrm{ml}$ and also closer to the findings of Gotlib et al. (2006) ${ }^{14}$ of 235 $\mathrm{ng} / \mathrm{ml}$ in United States in a study on IDA in CKD patients.

The gender differences in the levels ferritin and creatinine in this study were expected. The former is due to hormonal influence in females while the latter is because creatinine is mainly derived from the metabolism of Creatine in muscle and its generation is proportional to muscle mass which is more in females.

In a study on prevalence of anemia and its associated factors in patients with chronic kidney disease at Muhimbili National Hospital Dar es Salaam by Abdu J in Tanzania in $2012^{15}$ reported $43 \%$ of CKD patient met K/DOQI targets of adequate iron supply. While $17 \%$ were iron deficient and $37 \%$ had functional iron deficiency. However, in contrast to the findings in this current study, Hsu et al. (2002) $)^{16}$ in California reported $62.6 \%$ of CKD patients with anemia were iron deficient, as indicated by serum ferritin $<100 \mathrm{ng} / \mathrm{ml}$ and transferrin saturation (TSAT) $<20 \%$. Where by $25.8 \%$ had functional iron deficiency anemia as indicated serum ferritin $>100 \mathrm{ng} / \mathrm{ml}$ and $<20 \%$ TSAT. This upward trend of high Proportion of CKD patients with iron deficiency done elsewhere could be attributed to high sample size of $(15,837)$ in their previous study. When compared to our small sample size (125) investigated in the current study.

\section{Conclusions}

Serum creatinine, ferritin and TSAT were found to be significantly elevated in CKD patients while there was no difference in serum Iron and TIBC. The differences between males and female CKD patients in serum creatinine, ferritin and estimated creatinine clearance were found to be statistically significant. However, no statistical significant differences were noted in serum levels of iron, TIBC and TSAT between opposite sex. 


\section{Recommendation}

The study supports current KDOQI recommendation of replenishing iron stores in anaemic patients with chronic kidney disease. It is pertinent for clinicians to refer CKD patients as soon as diagnosis is made or suspected to nephrologists for early evaluation, prevention and treatment of anaemia in CKD.

\section{References}

1. Afolabi MO, Abioye-Kuteyi AE, Arogundade FA, Bello IS. Prevalence of chronic kidney disease in a Nigerian family practice population. South Afr Fam Pract 2009;51.

2. AIHW 2005. Chronic kidney disease in Australia, 2005. Australian Institute of Health and Welfare Cat. No. PHE 68. Canberra: AIHW. http://www.aihw.gov.au.

3. Levey AS, Coresh J. Should the K/DOQI definition of chronic kidney disease be changed? Am J Kidney Dis 2003;42:626-30.

4. Foundation NK. KDOQI clinical practice guideline for diabetes and CKD: 2012 update. Am J Kidney Dis 2012;60:85086.

5. Weiss G. Iron metabolism in the anemia of chronic disease. Biochim Biophys Acta 2009;1790:682-93.

6. Oyejide CO. Health research methods for developing country scientists. Leniks Limited; 1992.

7. Woods J, Mellon M. Thiocyanate method for iron: a spectrophotometric study. Industr Engin Chem Anal Ed 1941;13: 551-4.

8. Yee HY, Zin A. An AutoAnalyzer procedure for serum iron and total iron-binding capacity, with use of ferrozine. Clin Chem 1971;17:950-3.

9. Hoffman DR. Estimation of serum IgE by an enzyme-linked immunosorbent assay (ELISA). J Allergy Clin Immunol 1973; 51:303-7.

10. Slot C. Plasma creatinine determination a new and specific Jaffe reaction method. Scand J Clin Lab Investig 1965;17:3817.

11. Alebiosu CO, Ayodele OO, Abbas A, Olutoyin AI. Chronic renal failure at the Olabisi Onabanjo university teaching hospital, Sagamu, Nigeria. Afr Health Sci 2006;6:132-8.

12. Ulasi II, Ijoma CK. The enormity of chronic kidney disease in Nigeria: the situation in a teaching hospital in South-East Nigeria. J Trop Med 2010;2010.

13. Gangadhar T, Srikanth P, Suneetha Y. Predictive value of iron store markers in anemia of chronic kidney disease. J Chem Pharmaceutic Res 2010;2:400-10.

14. Gotloib L, Silverberg D, Fudin R, Shostak A. Iron deficiency is a common cause of anemia in chronic kidney disease and can often be corrected with intravenous iron. J Nephrol 2006; 19:161-7.

15. Juma A. Prevalence of Anemia and its associated factors in patients with Chronic Kidney Disease at Muhimbili National Hospital Dar es Salaam. Doctoral dissertation, Muhimbili University of health and Allied Sciences.

16. Hsu CY, McCulloch CE, Curhan GC. Iron status and hemoglobin level in chronic renal insufficiency. J Am Soc Nephrol 2002;13:2783-6. 